\title{
Effectiveness of the Pico-toning Technique for the Treatment of Melasma with a Low Fluence 1,064-nm Nd:YAG Laser in Asian Patients
}

\author{
Dong Gyu Kim \\ Seung Min Nam \\ Jin Soo Shin \\ Eun Soo Park
}

Department of Plastic and Reconstructive Surgery, Soonchunhyang University Bucheon Hospital, Soonchunhyang University College of Medicine, Bucheon, Korea
Received December 8, 2020

Accepted December 18, 2020

\footnotetext{
Correspondence

Eun Soo Park

Department of Plastic and Reconstructive, Soonchunhyang University Bucheon Hospital, 170 Jomaru-ro, Bucheon 14584, Korea

Tel.: +82-32-621-5319

Fax: +82-32-621-5016

E-mail: peunsoodaschmc.ac.kr

(C) Korean Society for Laser Medicine and Surgery

(@) This is an open access article distributed under the terms of the Creative Commons Attribution NonCommercial License (http://creativecommons.org/ licenses/by-nc/4.0) which permits unrestricted noncommercial use, distribution, and reproduction in any medium, provided the original work is properly cited.
}

\begin{abstract}
Background and Objectives
Melasma is an acquired pigmentary disorder characterized by brown or dark brown colored macules and patches which mostly involve the face. Compared to nanosecond lasers, picosecond lasers have fewer adverse effects on surrounding tissues and give better results for melanin fragmentation. The purpose of this study was to evaluate the efficacy of the pico-toning technique using a low fluence 1,064-nm Nd:YAG laser on melasma patients.
\end{abstract}

\section{Materials and Methods}

This study is a retrospective analysis of melasma cases treated using the pico-toning technique from June 2017 to November 2020. Based on photographic images, the modified Melasma Area and Severity Index (mMASI) score was blind evaluated by two independent plastic surgeons. Patient satisfaction was assessed through a 5-point Likert scale questionnaire after treatment sessions. All adverse effects and complications were reviewed based on medical records.

\section{Results}

A total of 23 patients were included in the study. The mMASI scores for baseline and 2 months after the last procedure were $5.1 \pm 1.4$ and $2.6 \pm$ 0.4 , respectively. The mean mMASI score reduced significantly after the treatment session $(p<0.05)$. The patient satisfaction score with the procedure was $3.8 \pm 1.0$. The subject satisfaction score and difference in the mMASI score before the procedure and 2 months after the last procedure showed a significant correlation. Adverse effects observed in this study were erythema $(n=1)$ and edema $(n=1)$.

\section{Conclusion}

The results of the study show that the pico-toning technique is effective in Asian patients with melasma. We believe that safety was enhanced by using low fluence, and thus better results were achieved with fewer adverse effects.

\section{Key words}

Picosecond; Laser toning; Pigmentation; Skin pigmentation; Melanosis 


\section{INTRODUCTION}

Melasma is an acquired pigmentary disorder and is characterized by brown or dark brown colored macules and patches. ${ }^{1}$ Although the exact cause of the onset is unknown, ultraviolet light, genetic predisposition, hormonal effect, pregnancy, and phototoxic drugs are the main factors. And it is also a cause of deterioration. ${ }^{2,3}$ It usually occurs on the face and rarely occurs in other areas.

The use of sunscreens to block ultraviolet light and topical anti-melanogenesis agents including hydroquinone, retinoic acid, glycolic acid and corticosteroid are common first-line treatments for melasma. ${ }^{4,5}$ Hydroquinone, which is a tyrosinase inhibitor, has been proven to be effective in the treatment of melasma but is known to be effective only in epidermal type melasma. ${ }^{6}$ A chemical peel to remove melanin is also one of the treatment options and glycolic acid and salicylic acid are available. However, this also has a disadvantage that it is not effective in mixed type or dermal type melasma and that recurrence may occur. ${ }^{7}$

Recently, laser-based treatment of hyperpigmentation conditions of the skin including melasma has been proposed as an adjunctive treatment. ${ }^{7}$ The main mechanism in the treatment of pigmentation using a laser is that photo-thermal energy targets the melanin pigment to cause "selective photothermolysis". 8 Lasers widely used in the treatment of pigmented skin include Q-switched Ruby laser, Q-switched alexandrite laser and Q-switched Nd:YAG laser. ${ }^{9.10}$ However, none of the laser treatments are consistently effective enough to become the gold standard, and complications including pain, erythema, and postinflammatory hyperpigmentation or hypopigmentation are frequently reported. ${ }^{10,11}$

Picosecond laser uses extremely short pulse duration, that is, 300-500 picosecond pulse duration. Because of these properties, it can deliver higher energies and shows a lower photothermal effect than other laser technologies with a longer pulse duration range. As a result, it has the advantage of minimizing post-procedure pain and minimizing skin discoloration after laser treatment. ${ }^{12}$ In the same fluence, the picosecond laser also causes more melanin fragmentation with higher energy than the nanosecond laser. ${ }^{13}$ Therefore, when using picosecond laser, melasma can be treated with low fluence and satisfactory results can be obtained with minimal side effects, ${ }^{14,15}$ which we refer to as the 'pico-toning technique'.

The purpose of this study was to evaluate the efficacy of the pico-toning technique using a low fluence picosecond 1,064-nm Nd:YAG laser in melasma patients.

\section{SUBJECTS AND METHODS}

\section{Subjects and study design}

This study is a retrospective analysis of the cases treated using picosecond 1064-nm laser treatment in patients diagnosed with melasma from June 2017 to November 2020. The patient's gender, age, clinical finding, the parameter for the performed procedure, and photographic images were collected from medical records. Patients with underlying skin disease, immunodeficiency, taking hormone replacement therapy, current pregnancy, breastfeeding were excluded from the study. In addition, patients who had been treated with topical agents such as retinoid, corticosteroid, hydroquinone within one month were excluded from the study. Photographic images were performed prior to the procedure and were taken 2 months after the last procedure. Photographic images were obtained under the same condition. 2D images of the whole face were taken in a natural manner (right lateral, right lateral $45^{\circ}$, central, left lateral $45^{\circ}$, left lateral). This study was approved by the Institutional Review Board of Soonchunhyang University Bucheon Hospital and performed in accordance with the Declaration of Helsinki.

\section{Laser treatment}

A picosecond Nd:YAG laser device, PICOCARE ${ }^{\circledR}$ (WON$\mathrm{TECH}$, Daejeon, Koreal was used in this study. Prior to initiation of treatment, a topical anesthetic agent $\left(E M L A^{\circledR}\right.$; Recipharm Karlskaga AB, Karlskoga, Sweden) was applied to the treatment area for 1 hour. After that, the topical anesthetic agent was wiped out and laser treatment was performed. Picosecond laser treatment was performed at a wavelength of 1,064-nm, 7-10 mm spot size, $0.5-0.8 \mathrm{~J} / \mathrm{cm}^{2}$ fluence, $10 \mathrm{~Hz}$ frequency, maximum 3 passes. The treatment protocol is presented in Table 1.

\section{Evaluation}

Pictures taken before the procedure and 2 months after the last procedure were evaluated by two blinded, independent plastic surgeons. The tool used for the efficacy assessment is the modified melasma area and severity index (mMASI) scoring system. Unlike conventional MASI, the mMASI score is calculated with two evaluation factors, including area of involvement (A) and darkness (D).

Table 1. Parameters of Pico-toning technique

\begin{tabular}{ccccc}
\hline $\begin{array}{c}\text { Wavelength } \\
(\mathrm{nm})\end{array}$ & $\begin{array}{c}\text { Spot size } \\
(\mathrm{mm})\end{array}$ & $\begin{array}{c}\text { Fluence }(\mathrm{J} / \\
\left.\mathrm{cm}^{2}\right)\end{array}$ & $\begin{array}{c}\text { Frequency } \\
(\mathrm{Hz})\end{array}$ & Pass \\
\hline 1,064 & $7-10$ & $0.5-0.8$ & 10 & Maximum 3 \\
\hline
\end{tabular}


Area of involvement are scored as follows : $0=$ absent, $1 \leq 10 \%, 2=10 \%-29 \%, 3=30 \%-49 \%, 4=50 \%-69 \%, 5=$ $70 \%-89 \%$, and $6=90 \%-100 \%$. Darkness are scored as follows: 0 = absent, 1 = slight, 2 = mild, 3 = marked, and $4=$ severe. Total range of score is $0-24$. The evaluation was conducted by dividing the area into Forehead(f), right malar area $(\mathrm{rm})$, left malar area $(\mathrm{lm})$, and chin(c), and the calculation formula is as follows. ${ }^{16}$

Modified MASI total score $=$

$0.3^{*} A(f) * D(f)+0.3^{*} A(r m) * D(r m)+0.3 * A(l m) * D(l m)+$ $0.1^{*} A(c) * D(c)$

Two months after the last procedure, the patient's satisfaction with the treatment was evaluated. Subject satisfaction was evaluated on a 5-point Likert scale questionnaire. 11 = Very unsatisfied, 2 = Unsatisfied, $3=$ Neutral, 4 = Satisfied, 5 = Very satisfied) A correlation analysis study was conducted between the subject satisfaction score and difference in the mMASI score before the procedure and 2 months after the last procedure.

All adverse events and complications, including erythema, edema, bullae, post inflammatory hyperpigmentation, and hypopigmentation, on medical records were reviewed during treatment and visitation.

\section{Statistical analysis}

Statistical analysis was performed using Data were analyzed using SPSS Statistics for Windows, Version 26.0 (IBM Corp, Armonk, NY, USA). The Wilcoxon-signed rank test was used to compare the mMASI scores of pre-

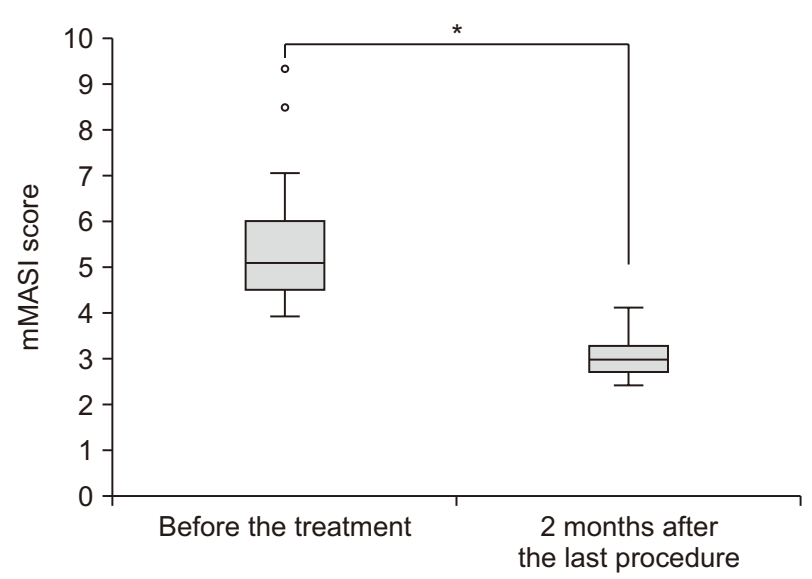

Fig. 1. The modified melasma area and severity index (mMASI) score of baseline and 2 months after the last procedure. The baseline and 2 months after the last procedure are $5.1 \pm 1.4$ and $2.6 \pm 0.4$, respectively. The mean mMASI score reduced significantly. ${ }^{*} p<$ 0.05 . treatment and 2 months post-treatment visits. Spearman correlation test was used to compare the correlation between the subject satisfaction score and the difference in the mMASI score before the procedure and 2 months after the last procedure. Descriptive statistics are expressed as means \pm standard deviations. A $p$-value of less than 0.05 was considered statistically significant.

\section{RESULTS}

A total of 23 patients who were clinically diagnosed with melasma were included in the study. The mean patient age was $51.1 \pm 9.3$ years. The baseline mMASI score was $5.1 \pm 1.4$. The mMASI score performed 2 months after the last procedure was $2.6 \pm 0.4$ (Fig. 1). Following the laser treatment, the mean mMASI score decreased significantly. $(p<0.05)$ Treatment sessions that the patients underwent the pico-toning technique was $5.0 \pm 1.3$. After treatment, patients' satisfaction with the procedure was $3.8 \pm 1.0$, with 4 points (satisfied) being the most frequent. The results of Spearman's correlation coefficient showed significant relationships between the subject satisfaction score and difference in the mMASI score before the procedure and 2 months after the last procedure $(r=0.844, p$ $<0.001$ ) (Fig. 2). The photographic finding of a case before the treatment and 2 months after the last procedure is presented (Fig. 3). Adverse effects observed in this study were erythema $(n=1)$ and edema $(n=1)$, and no recurrence, post-inflammatory hypopigmentation, or hyperpigmentation was observed. The demographic data of the patients included in the study have been listed in Table 2.

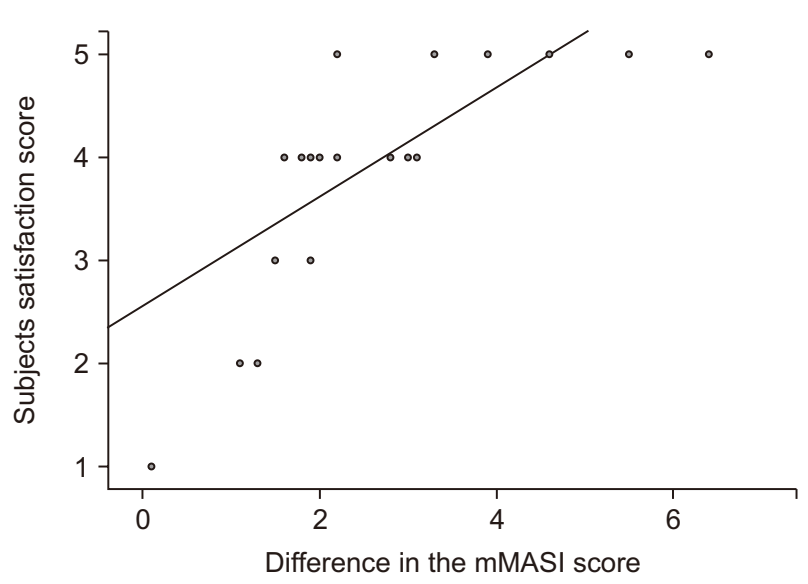

Fig. 2. Scatter plot of the subject satisfaction score and difference in the mMASI score. The scatter plot shows significant relationships between the subject satisfaction score and difference in the mMASI score before the procedure and 2 months after the last procedure $(\mathrm{r}=$ $0.844, p<0.001)$. 


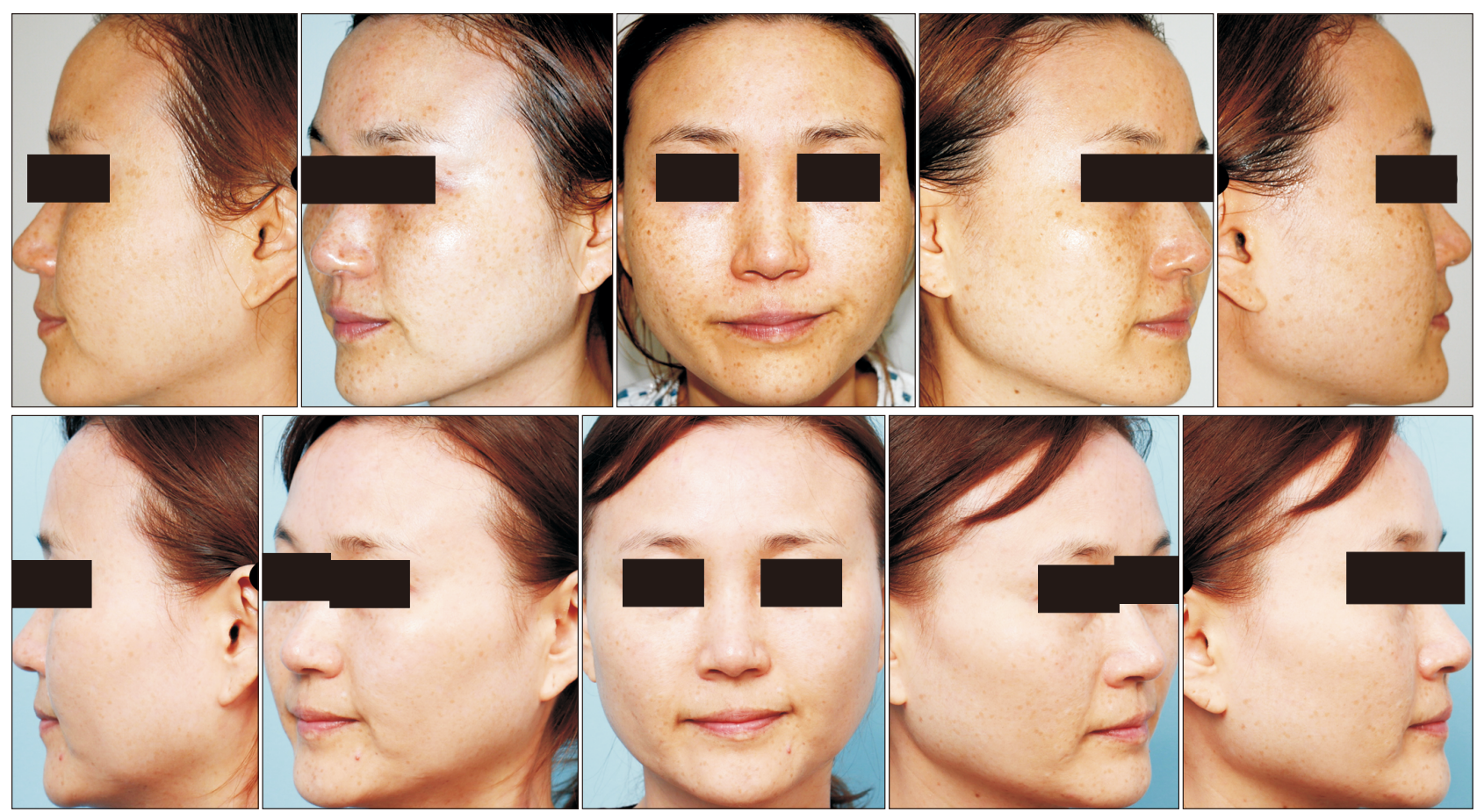

Fig. 3. Photographic finding of a case before and after the treatment. Before the treatment (upper) and 2 months after the last procedure (lower).

Table 2. Demographic characteristics

\begin{tabular}{lc}
\hline \multicolumn{1}{c}{ Charateristics } & $\begin{array}{c}\text { Results } \\
\text { (Mean } \pm \text { SD or N (\%)) }\end{array}$ \\
\hline Age & $51.1 \pm 9.3$ \\
Gender & \\
Female & $23(100 \%)$ \\
Adverse effect & \\
Erythema & $1(4.3)$ \\
Edema & $1(4.3)$ \\
Bullae & $0(0)$ \\
Post-inflammatory hyperpigmentation & $0(0)$ \\
Post-inflammatory hypopigmentation & $0(0)$ \\
\hline
\end{tabular}

$\mathrm{SD}$, standard deviation.

\section{DISCUSSION}

Selective photothermolysis, presented in 1983, is the concept that specific wavelengths can be used to target specific chromophores. ${ }^{8}$ Using a duration shorter than the target's thermal relaxation time in terms of pulse duration can reduce damage to the surrounding tissue. With the advent of the picosecond laser, it was found that target destruction is possible in a state where there is little heating or damage to the surrounding tissue in the pulse duration range of 10-100 picoseconds, and this leads to the concept of photomechanical effect. ${ }^{17}$ Laser-induced optical breakdown (LIOB) refers to the process that plasma is generated as a result of free "seed" electrons by multiphoton absorption or by thermionic emission, ${ }^{18}$ leading to breakdown. ${ }^{19}$ In the skin, melanin provides free seed electrons by laser-heated melanin, and the resulting plasma forms vacuoles in the epidermal layer. Based on these theoretical backgrounds, a picosecond laser can be judged as an appropriate treatment option for melasma.

Research on the treatment of melasma using lasers has continued for the past decade, especially the treatment of melasma using Q-switched Nd:YAG laser..$^{20-22}$ In these studies, the treatment showed effective results, but post-laser hyperpigmentation has occurred in several cases, and there has been frequent recurrence. ${ }^{23,24}$ In a comparative study of split face treatment using Qswitched Nd:YAG laser and picosecond laser, picosecond laser showed faster and better melasma clearance rate..$^{25}$ Another study proved that the use of hydroquinone cream treatment in combination with a 1,064-nm picosecond laser showed better results than when using hydroquinone cream alone, and also proved the safety of using a $1064 \mathrm{~nm}$ picosecond laser. ${ }^{26}$

Picosecond laser can target not only melanin but also hemoglobin, and dermal hemorrhage has been confirmed histologically. ${ }^{19}$ Therefore, it is essential to control fluence for proper energy delivered to reduce adverse effects. In 1999, Goldberg et al. introduced the concept of laser toning for the first time by conducting skin resurfac- 
ing using low fluence Nd:YAG. ${ }^{27}$ In subsequent studies, the application of low fluence showed an effect on skin rejuvenation and skin pigmentation at the same time. .4,28,29 $^{-1}$ Kang et al. introduced a dual toning technique combining two modes, nanosecond and microsecond, using 1,064$\mathrm{nm}$ Nd:YAG. ${ }^{30}$ We subsequently named it the "pico-toning technique" as laser toning using a picosecond laser.

This study demonstrates the efficacy and safety of picotoning technique with a low fluence picosecond 1,064$\mathrm{nm} \mathrm{Nd:YAG} \mathrm{laser} \mathrm{in} \mathrm{Asian} \mathrm{female} \mathrm{melasma} \mathrm{patients.}$ The limitations of this study are that the study design is a retrospective study of treatment protocol solely with picotoning technique, the number of patients is small, and there is a lack of long-term follow-up data after the end of treatment. We look forward to conducting large-scale prospective studies in the future, including comparisons with other laser or topical treatment options for melasma.

\section{ACKNOWLEDGEMENTS}

This work was supported by the Soonchunhyang University Research Fund.

\section{CONFLICT OF INTEREST}

The authors declare no conflicts of interest.

\section{REFERENCES}

1. Sheth VM, Pandya AG. Melasma: a comprehensive update: part I. J Am Acad Dermatol 2011;65:689-97.

2. Grimes PE. Melasma. Etiologic and therapeutic considerations. Arch Dermatol 1995;131:1453-7.

3. Barankin B, Silver SG, Carruthers A. The skin in pregnancy. J Cutan Med Surg 2002;6:236-40.

4. Gupta AK, Gover MD, Nouri K, Taylor S. The treatment of melasma: a review of clinical trials. J Am Acad Dermatol 2006;55:1048-65.

5. Lynde CB, Kraft JN, Lynde CW. Topical treatments for melasma and postinflammatory hyperpigmentation. Skin Therapy Lett 2006;11:1-6.

6. Amer M, Metwalli M. Topical hydroquinone in the treatment of some hyperpigmentary disorders. Int J Dermatol 1998;37:44950.

7. Sheth VM, Pandya AG. Melasma: a comprehensive update: part II. J Am Acad Dermatol 2011;65:699-714.

8. Anderson RR, Parrish JA. Selective photothermolysis: precise microsurgery by selective absorption of pulsed radiation. Science 1983:220:524-7.

9. Anderson RR, Margolis RJ, Watenabe S, Flotte T, Hruza GJ,
Dover JS. Selective photothermolysis of cutaneous pigmentation by Q-switched Nd: YAG laser pulses at 1064, 532, and 355 nm. J Invest Dermatol 1989;93:28-32.

10. Jones CE, Nouri K. Laser treatment for pigmented lesions: a review. J Cosmet Dermatol 2006;5:9-13.

11. Gokalp H, Akkaya AD, Oram Y. Long-term results in lowfluence 1064-nm Q-switched Nd:YAG laser for melasma: is it effective? J Cosmet Dermatol 2016;15:420-6.

12. Saedi N, Metelitsa A, Petrell K, Arndt KA, Dover JS. Treatment of tattoos with a picosecond alexandrite laser: a prospective trial. Arch Dermatol 2012;148:1360-3.

13. Zysset B, Fujimoto JG, Puliafito CA, Birngruber R, Deutsch TF. Picosecond optical breakdown: tissue effects and reduction of collateral damage. Lasers Surg Med 1989;9:193-204.

14. Alabdulrazzaq H, Brauer JA, Bae YS, Geronemus RG. Clearance of yellow tattoo ink with a novel 532-nm picosecond laser. Lasers Surg Med 2015;47:285-8.

15. Brauer JA, Kazlouskaya V, Alabdulrazzaq H, Bae YS, Bernstein $\mathrm{LJ}$, Anolik R, et al. Use of a picosecond pulse duration laser with specialized optic for treatment of facial acne scarring. JAMA Dermatol 2015;151:278-84.

16. Pandya AG, Hynan LS, Bhore R, Riley FC, Guevara IL, Grimes $P$, et al. Reliability assessment and validation of the Melasma Area and Severity Index (MASI) and a new modified MASI scoring method. J Am Acad Dermatol 2011;64:78-83, 83.e1-2.

17. Ho DD, London R, Zimmerman GB, Young DA. Laser-tattoo removal--a study of the mechanism and the optimal treatment strategy via computer simulations. Lasers Surg Med 2002;30:389-97.

18. Varghese B, Bonito V, Jurna M, Palero J, Verhagen MH. Influence of absorption induced thermal initiation pathway on irradiance threshold for laser induced breakdown. Biomed Opt Express 2015;6:1234-40.

19. Tanghetti EA. The histology of skin treated with a picosecond alexandrite laser and a fractional lens array. Lasers Surg Med 2016;48:646-52.

20. Zhou X, Gold MH, Lu Z, Li Y. Efficacy and safety of Q-switched 1,064-nm neodymium-doped yttrium aluminum garnet laser treatment of melasma. Dermatol Surg 2011;37:962-70.

21. Park KY, Kim DH, Kim HK, Li K, Seo SJ, Hong CK. A randomized, observer-blinded, comparison of combined 1064-nm Qswitched neodymium-doped yttrium-aluminium-garnet laser plus 30\% glycolic acid peel vs. laser monotherapy to treat melasma. Clin Exp Dermatol 2011;36:864-70.

22. Lee MC, Chang CS, Huang YL, Chang SL, Chang CH, Lin YF, et al. Treatment of melasma with mixed parameters of 1,064-nm Q-switched Nd:YAG laser toning and an enhanced effect of ultrasonic application of vitamin C: a split-face study. Lasers Med Sci 2015:30:159-63.

23. Vachiramon V, Sirithanabadeekul P, Sahawatwong S. Low- 
fluence Q-switched Nd: YAG 1064-nm laser and intense pulsed light for the treatment of melasma. J Eur Acad Dermatol Venereol 2015;29:1339-46.

24. Chan NP, Ho SG, Shek SY, Yeung CK, Chan HH. A case series of facial depigmentation associated with low fluence $Q$-switched 1,064nm Nd:YAG laser for skin rejuvenation and melasma. Lasers Surg Med 2010;42:712-9.

25. Lee MC, Lin YF, Hu S, Huang YL, Chang SL, Cheng CY, et al. A split-face study: comparison of picosecond alexandrite laser and Q-switched Nd:YAG laser in the treatment of melasma in Asians. Lasers Med Sci 2018;33:1733-8.

26. Chalermchai T, Rummaneethorn P. Effects of a fractional picosecond $1,064 \mathrm{~nm}$ laser for the treatment of dermal and mixed type melasma. J Cosmet Laser Ther 2018;20:134-9.

27. Goldberg D, Metzler C. Skin resurfacing utilizing a low-fluence Nd:YAG laser. J Cutan Laser Ther 1999;1:23-7.

28. Choi JE, Lee DW, Seo SH, Ahn HH, Kye YC. Low-fluence Qswitched Nd:YAG laser for the treatment of melasma in Asian patients. J Cosmet Dermatol 2018;17:1053-8.

29. Kaminaka C, Furukawa F, Yamamoto Y. The clinical and histological effect of a low-fluence Q-switched 1,064-nm neodymium: yttrium-aluminum-garnet laser for the treatment of melasma and solar lentigenes in Asians: prospective, randomized, and split-face comparative study. Dermatol Surg 2017;43:112033.

30. Kang H, Kim J, Goo B. The dual toning technique for melasma treatment with the $1064 \mathrm{~nm} \mathrm{Nd}$ : YAG laser: a preliminary study. Laser Ther 2011;20:189-94.

How to cite this article: Kim DG, Nam SM, Shin JS, Park ES. Effectiveness of the pico-toning technique for the treatment of melasma with a low fluence 1,064-nm Nd:YAG Laser in Asian patients. Med Lasers 2020;9:166-171. https:// doi.org/10.25289/ML.2020.9.2.166 